（日本化学会誌, 1977, (2), p. 191 193）

\title{
黒鉊硝酸塩層間化合物の加熱処理により得られる はく離状黒鉛のフッ素化反応
}

\author{
(1976 年 7 月 27 日受理)
}

渡辺信淳・喜田康・川口俊夫*

フレイク状天然黒鉛（20 50メッシュ）を発煙硝酸中に浸漬し，引きつづき $100^{\circ} \mathrm{C}$ 以上の温度で加 熱処理することにより，はく離状黒鉛が得られた。これは，原料黒鉛よりる大きな比表面積と格子ひず みをもっている。また，はく離状黒鉛のフッ菜化は原料黒鉛の場合よりる短時間で行なわれた。。

フレイク状天然黒鉛のフッ素化反応においては，反応過程で生成したフッ化黒鉛被膜中へのフッ菜分 子の拡散が反応の律速となるのに対し，はく離状黒鉛では反応界面でのフッ索分子の解離が反応の律速 となることがわかった。

はく離状黑鉛から得られたフッ化黒鉛は，原料黒鉛から得られたものよりも面間隔が広く，結晶性す よく，乙かる高いフッ素含有率をもつ。

\section{1 緒霄}

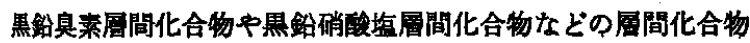
壮，一般炕不安定な化合物であり，空気中代故置して層間物筫を 十分飞放出させると安定な残留化合物となる゙。これらの残留化

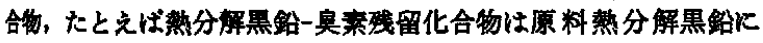

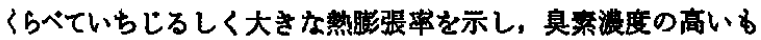

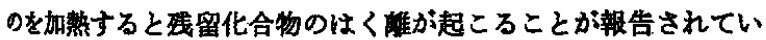

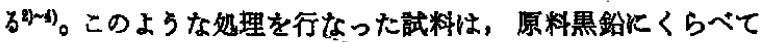
高い此表面樍，高い化学㕅応性などの異なった性質を示すことが 期待しらる。

黑鉛のフッ来化反応においては，原料にフレイク状の試料を用 いると，反応過程で生成したフッ化黒鈶被瞙中へのフッ秦分子の 其散が応の律速となることが知られ(

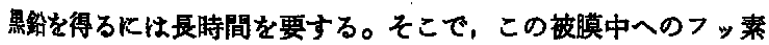
公子の㹡散を容易にし，短時間で高フッ莱化率のフッ化黑鉛を得 ろためあらかしめフレイク状天然黒鉛を発煙硝酸中に漫漬して

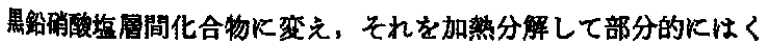
崔させた照鈶（exfoliated graphite, 以下E.G. と略記する）を 作成し、それをフッ秦化試料として用いた。

この前処理がフッ化黑鉻生成反応，生成フッ化䆀鉛の結晶構造

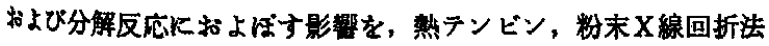
脑よび DTA を用いて検討した。

\section{2 实駼方 法}

原料炡，マダガスカル産天然黑銛（浮遊選鉱法により灰分 4.7

* 京都大学工学部工業化学教室, 606 京都市左京区吉田本町

1) G. Hennig, J. Chem. Phys., 20, 1443(1952).

2) J. E. Brocklehurst, Nature, 194, 247(1962).

3) W. H. Martin, J. E. Brocklehurst, Carbon, 1, 133(1964).

4) 矢島聖使，天井雄雄，青木興一，材料， 18，1004(1969).

5）渡辺傍淳，高盘正之，案田康，日化，1974，885.
\%にしたるの) $20 \sim 50$ メッシュ粉末を用いた。黑鉛試料 $500 \mathrm{mg}$ を発社硝酸 $2 \mathrm{~m} l$ 中心所定の時間温渍したのち，100，200，300， $400,550^{\circ} \mathrm{C}$ の各温度で 10 分問加熱して黑鉛硝酸海層間化合物を

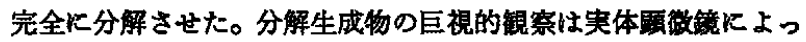
て行ない，また，その比表面屓は定压吸着法 0, 05 0.3 の笽囲で BET プロットにより求めた。また，結晶性やひずみなどの構造 に関する情報怢X線回折法により調べた。

\section{3 結果および考察}

\subsection{E. G. の生成}

E. G. の題徽鏡観宗を写真 1 亿示す。黒鉛硝酸塩層間化合物を 急激们加熱すると、はく離現象が観察されるが，加第処理温度が $100^{\circ} \mathrm{C}$ 以下のときには汪とんど見られない。

E. G. 生成の加熱処理条件と比表面䅡の関保を表 1 亿示した。

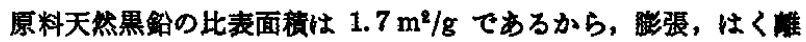
させると 10 倍以上の比表面積となる。加愁观理温度を上げると， 比表面稳恃若千增加する傎向が見られるが，漫㴖時間を变化させ ても、ほとんど比表面稳の㚆化は見られなかった。このことは，

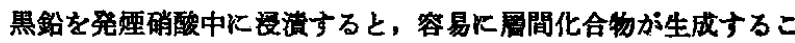
とによるものである゙。また，E.G. を再度数回，同様の处理をく ク返しても，比表面積は汪とんと变化しなかった。 また，黒鉐硝 酸塩間間化合物を，硝酸の沸点付近 $\left(80 \sim 90^{\circ} \mathrm{C}\right)$ で加愁しても E. G.を得ることはできなったか，硝酸の沸点付近で周間化合 物を 4 時間程度加熱しつづけたのち，ガスの発生がなくなった試 料》を $400^{\circ} \mathrm{C}$ で加熱すると，同栐な E.G. が得られた。さらK,

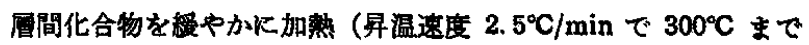
加熱）しても，同棣な膨張、はく離現象が維察された。

6)硝酸の涨点は $86^{\circ} \mathrm{C}$ である.

7）発煙硝酸を使った場合，2ステージてのるのが得られる とい5.

8）愚鉛硝酸塭残留化合物になっていると考えられる. 


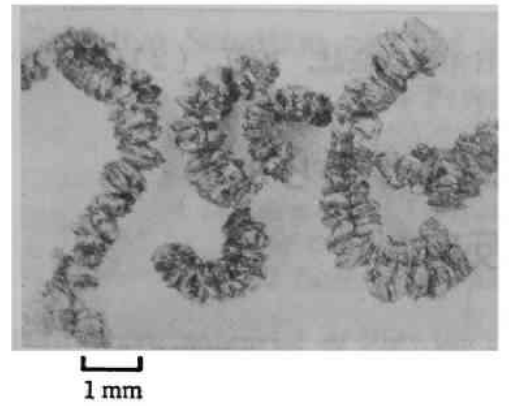

Photo. 1 Exfoliated graphite

(Specific surface area : $22 \mathrm{~m}^{2} / \mathrm{g}$ )

Table 1 Variation of specific area of exfoliated graphite with immersion time in huming nitric acid and subsequent heat-treatment temperature (Specific area of the original graphite $1.7 \mathrm{~m}^{2} / \mathrm{g}$ )

\begin{tabular}{ccc}
$\begin{array}{c}\text { Immersion } \\
\text { time }\end{array}$ & $\begin{array}{c}\text { Heating } \\
\text { temperature } \\
\left({ }^{\circ} \mathrm{C}\right)\end{array}$ & $\begin{array}{c}\text { Specific area } \\
\left(\mathrm{m}^{2} / \mathrm{g}\right)\end{array}$ \\
\hline $1 \mathrm{~min}$ & 200 & 22 \\
$1 \mathrm{~min}$ & 300 & 22 \\
$1 \mathrm{~min}$ & 400 & 27 \\
$1 \mathrm{~min}$ & 550 & 28 \\
$1 \mathrm{~min}$ & 300 & 22 \\
$1 \mathrm{hr}$ & 300 & 21 \\
1 day & 300 & 19
\end{tabular}

元素分析の結果，E.G. は空素を含まないことが確認された。 ここでは, 結晶の性質だけに基づく回折線幅を求めるために学 振法9)により高純度ケイ素を内部標準とし, 測定条件に基つく広

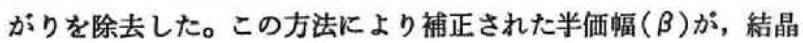
格子ひずみと結晶子の大きさによる広がりからなり立っているる のとすれば, 次式が成立する。

$$
\left.\beta \cos \theta=\eta \sin \theta+K \lambda / L_{\mathrm{c}}{ }^{10}\right)
$$

ここで, $\theta$ は回折角 $\left(^{\circ}\right), \eta$ は結晶格子ひずみバラメーターで 面間隔の変化に相当する。Kは形状因子, $\lambda$ はX線の波長で, $L_{\mathrm{c}}$ は結晶子の $c$ 軸方向の厚み (㐫) である。上式を使って, E. G. K ついて, $\eta$ と $L_{\mathrm{c}}$ を求めた結果を, 天然黒鉛のそれらと比較して 表 2 に示した。 $L_{\mathrm{c}}$ はいずれる $1000 \AA$ 以上であり，E.G. の格子 ひずみ(ク)は天然黒鉛よりも大きな值を示した。このひずみは, 温度の上昇とともに増加する傾向が見られた。稻垣は, 黒鉛硝酸 塩残留化合物の面間隔は黒鉛のそれよりる狭く，10２0 ${ }^{\circ} \mathrm{C}$ 付近 に黒鉛には見られない新たなX線回折線ビークが出現することを 報告している ${ }^{11)}$ 。E.G.の (110) 回折線から学振法によって求め た $a$ 軸方向の見かけの結晶子 $L_{\mathrm{a}(110)}$ は $1000 \AA$ 以上であり, ほ とんど変化は見られなかった。

\subsection{E. G. のフッ素化}

E. G. と原料黒鉛をフ ッ素圧 $200 \mathrm{mmHg}$ 下， $2.5^{\circ} \mathrm{C} / \mathrm{min} て ゙$ 昇 温し、フッ素化したさいの熱重量曲線を図1K示した。E.G. は 若干低温でフッ素化が始まり, 反応率す温度とともに急上昇する。

9）岸素材料研究会編集，“岩素材料入門”，(1972)p.184.

10）水島三知, 岩素, 52, 9(1968).

11）稲垣道夫, Carbon, 5, 317(1967).
Table 2 Lattice strain $(\eta)$ and crystallite size $\left(L_{\mathrm{c}}\right)$ of the original and exfoliated graphites

\begin{tabular}{lccr}
\multicolumn{1}{c}{ Sample } & $\begin{array}{l}d \text { Spacing } \\
(002)(\AA)\end{array}$ & $\eta$ & $\begin{array}{r}L_{\mathrm{c}} \\
(\AA)\end{array}$ \\
\hline $\begin{array}{l}\text { Original graphite } \\
\begin{array}{l}\text { Exfoliated graphite } \\
\text { obtained at } 200^{\circ} \mathrm{C}\end{array}\end{array}$ & 3.353 & 0.0019 & $>1000$ \\
$\begin{array}{l}\text { Exfoliated graphite } \\
\text { obtained at } 400^{\circ} \mathrm{C}\end{array}$ & 3.351 & 0.0054 & $>1000$ \\
& & 0.0062 & $>1000$
\end{tabular}

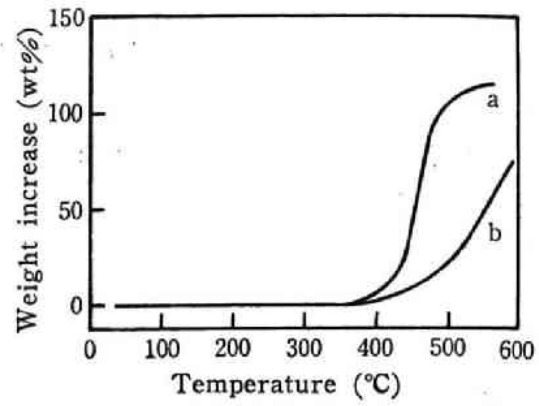

Fig. 1 TG curves for fluorination of the exfoliated and original graphites

$P_{\mathrm{F}_{2}}: 200 \mathrm{mmHg}$, Heating rate $: 2.5^{\circ} \mathrm{C} / \mathrm{min}$ a : Exfoliated graphite b : Original graphite

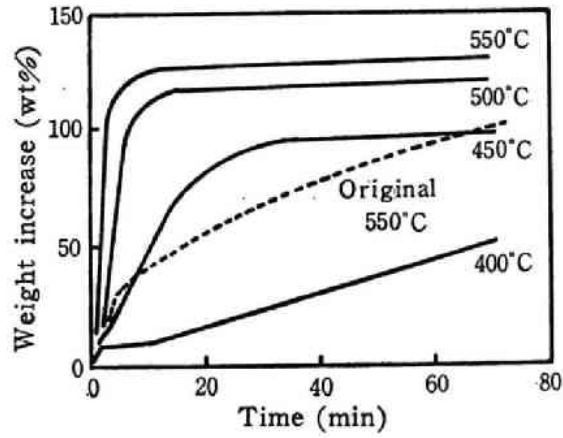

Fig. 2 Fluorination of the exfoliated and original graphites

$$
P_{\mathrm{F} 2}: 200 \mathrm{mmHg}
$$

また，E.G. とついてフッ素圧 $200 \mathrm{mmHg}$ 下, 一定温度での重

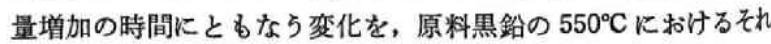
と比較して图 2 に示した。E.G.は，原料黒鉛と異なり，60 wt\% の重量增加にいたるまで粉末黒鉛と同様な直線的重量增加を示 す。そこで，E.G. の反応速度が天然黒鉛と同様に 2 次元の Jander の造膜反応のモデル12) (次式) が適用できるとしてプロ， トすると，いずれの場合もよい直線性が得られた。

$$
\left[1-(1-x)^{1 / 2}\right]^{n}=k t
$$

ここで, $x$ は反応率を表わし $\mathrm{C}: \mathrm{F}=1: 1$ のときに $x=1$ とな $\eta, t$ は時間(分)である。

原料黒鉛の揚合には既報ら)之同様，直線の傾きが $1 / 2(n=2)$ て あり,フッ素分子の拡散が律速であるのに対し， E.G. では，そ の傾きから $n=1$ となり, 表面反応律速と考えられる。E.G.の

12）渡辺信淳, 高島正之, 工化, 74, 1788(1971). 


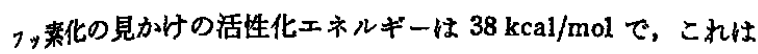
7,来分子の解離エネルギー $37.7 \mathrm{kcal} / \mathrm{mol}$ 亿近い値であるから， フッ秦分子の解離反応が律速になると考えられる。

黒鋯のフッ事化過程の顕徽鏡観察から，反応中にクラックなど

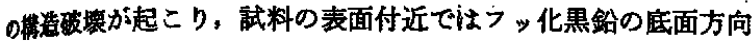
加わ，フッ素分子が供給されると考えられている19)。フレイク 状天然黑鈆を膨張，はく離させると， $c$ 軸方向の結晶子の大きさ 㧅さ〈なるために，フッ化黒鉛底面方向からの反応界面への〉 、莱分子の供耠が容易になる。また，E.G. から生成したフッ化

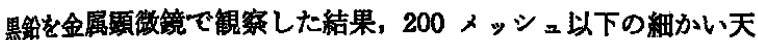
然黑鉿から生成したフッ化黑鉛と同様なフッ素化状態が観察され

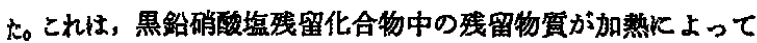
故出されるさいに，黒鉛内部に新しい格子欠陮や粒界をつくり出 し、これらの点が新たなフッ素化反応の開始点となるためと考え られる。

このよろに，X線回折法によって求めた E.G. の $a$ および $c$ 軸 方向の見かけの結晶子の大きさは $1000 \AA$ 以上でフレイク状天然 黑鉙の揚合との比較はでさなかったが，E.G. からフッ化黑鈶を 生成与る反応江，粉末黑鉛と同様にフッ莱分子の解離反応が律速 卵觜となり，短時間で高フッ素化率のフッ化黑鉿が得られること がかかった。

3.3 生成フッ化黑鉛の性露

原料黑鈴と E.G. か.ら生成したフッ化黑鉛（反度条件；反応

13）渡辺信注，竹中敬恭，嵌亲材料学会第 1 回年会要旨集，p. 114(1974).
Table $3 \mathrm{X}$-ray parameter, $\mathrm{F} / \mathrm{C}$ ratio and decomposition temperature $T$ for two kinds of graphite fluoride which were obtained by the fluorination at $570^{\circ} \mathrm{C}$ under the fluorine gas pressure of 200 Torr for $2 \mathrm{hr}$

$\begin{array}{lccccc}\text { Sample } & d_{001} \overbrace{(\AA)} & \beta_{001}\left({ }^{\circ}\right) & \begin{array}{c}\text { X-ray } \\ \text { ratio }\end{array} & \overbrace{T_{0}\left({ }^{\circ} \mathrm{C}\right)} T_{T_{m}\left({ }^{\circ} \mathrm{C}\right)} \\ \begin{array}{l}\text { Graphite fluoride } \\ \text { made from the } \\ \text { original graphite }\end{array} & 6.03 & 2.7 & 0.86 & 532 & 585 \\ \begin{array}{c}\text { Graphite fluoride } \\ \text { made from the } \\ \text { exfoliated graphite }\end{array} & 6.28 & 2.5 & 0.92 & 536 & 590\end{array}$

温度 $570^{\circ} \mathrm{C}, 7$ 莱压 $200 \mathrm{mmHg}, 26$ 時間) のX線回折によって 求めた (001) の面間隔 $d_{001}{ }^{16)}$ とその半洒幅 $\beta_{001}$ およびフッ菜含 有率を表 3 飞示した。また, それらの常厌下アルゴン等用気中で 加熱したさいの分解の開始温度 T. (DTA Kおける発熱ピークの 開始温度) とピーク極大温度 $T_{\mathrm{m}}$ を示した。なお，2 種類の試料 はいずれる重量增加が飽和状態になっているすのである。

表から明らかなよらK， E.G. から得られたフッ化黑鉛の方が

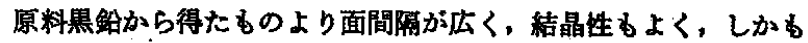
高いフッ素含有率をるつ。TAからは，2種類のフッ化黒鉛で 䫒著な臬いはないが，E.G. から得られたフッ化黒鉿の方が若千， 熟的に安定である。

14） フッ化黑鉛の屏開距離を示子.

\title{
Fluorination of Exfoliated Graphite Obtained by Heat-treatment of Graphite-nitrate Lamellar Compound
}

\author{
Nobuatsu Watanaee, Yasushi Kita and Toshio Kawaguch \\ Department of Industrial Chemistry, Faculty of Engineering, Kyoto University; \\ Yoshida, Sakyo-ku, Kyoto-shi 606 Japan
}

By the immersion of flaky natural graphite (20 50 meshes) into huming nitric acid and subsequent heat-treatment above $100^{\circ} \mathrm{C}$, the exfoliated graphite was obtained. It had much bigger specific area (Table 1) and larger lattice strain (Table 2) than the original graphite.

On the exfoliated graphite, much faster fluorination was achieved (Fig. 1 and Fig. 2).

The dissociation of fluorine molecules to atoms was found to be a rate-determining step in the formation of graphite fluoride from the exfoliated graphite, whereas the process of diffusion of fluorine molecules was the rate-determining step on the original flaky graphite.

The graphite fluoride obtained from the exfoliated graphite had larger interlayer spacing, better crystallinity and larger fluorine content than that from the original graphite (Table 3 ). 